\section{The Western Thoracic Surgical Association}

\section{Announcement of 2003 Annual Meeting}

$\mathrm{T}$ The Twenty-ninth Annual Meeting of The Western Thoracic Surgical Association will be held June 18-21, 2003, at La Costa Resort in Carlsbad, California. The scientific sessions are open to all duly qualified physicians. Participation in other Association activities for members, invited guests, and program participants will require payment of a social registration fee.

\section{Requests for Meeting Information}

Meeting preregistration and hotel registration forms are available from:

\author{
The Western Thoracic Surgical Association \\ Thirteen Elm Street \\ Manchester, Massachusetts 01944-1314 \\ 978-526-8330; fax: 978-526-7521 \\ wtsa@prri.com \\ www.westernthoracic.org
}

\section{Material for the Program}

Scientific papers will be considered from members and nonmembers. Member sponsorship is not necessary. Abstracts of proposed papers must have been received by the Program Chairman on or before January 10, 2003, and must have been accompanied by a Transmittal of Abstract Form.

All abstracts submitted must be in the structured format as required by The Journal of Thoracic and Cardiovascular Surgery. The structured abstract is to contain the following major headings: Objective(s), Methods, Results, and Conclusions, and should clearly reflect the content of the completed paper. No reference should be made on the abstract to the names or institutions of the authors. Abstracts must represent unpublished work not previously presented at a major scientific meeting. Unless specified otherwise, the first named author will receive correspondence, give a tenminute presentation of the paper, and close the discussion. Instructions and Abstract Transmittal Forms are available from:

\author{
Chairman, Program Committee \\ The Western Thoracic Surgical Association \\ Thirteen Elm Street \\ Manchester, Massachusetts 01944-1314 \\ 978-526-8330 \\ wtsa@prri.com
}

Successful essayists must send the complete manuscript directly to The Journal of Thoracic and Cardiovascular Surgery and must not exceed 3000 words without illustrations. Electronic submissions are to be sent to: http://jtcvs.editorialmanager.com where complete instructions are also available. The essay length must be reduced appropriately when figures or tables are included.

\section{Samson Resident Prize Essay}

The Association offers a prize for the best manuscript on a topic of interest to thoracic surgeons in honor of Paul C. Samson, MD. Candidates for the prize must be in a training program in the United States or Canada. The one essayist whose abstract, manuscript, and presentation are judged most outstanding will receive a $\$ 2000$ cash award following the presentation of all papers in California. The conditions for abstract submission, presentation, and publication as described above will apply. In addition, the Samson Resident Prize Essay box in the lower left hand corner of the form should be checked. A covering letter from the Chief of Service of the training program indicating the individual's year of training and the proportion of the work performed by the resident must be submitted. The authors of the abstracts chosen for the program will make up the finalists and will be notified by midFebruary 2003 that they must submit six completed manuscripts for review by the Prize Essay Committee. The Prize Essay committee will make its selection following the presentation of all papers.

\section{Application for Membership}

Applications for membership in the Association must have been received by the Membership Committee Chairman no later than March 1, 2003, to be considered at the following annual meeting. Applicants must be sponsored by three members of the Association who are not members of the Membership Committee. Application forms will be issued only to sponsoring members.

Address correspondence to:

Chairman, Membership Committee

The Western Thoracic Surgical Association

Thirteen Elm Street

Manchester, Massachusetts 01944-1314

978-526-8330; fax: 978-526-4018 